\title{
Redução populacional de trigo no rendimento e na qualidade fisiológica das sementes ${ }^{1}$
}

\author{
Population reduction of wheat for yield and the physiological quality of seeds
}

\author{
Ana Paula Piccinin Barbieri², Thomas Newton Martin ${ }^{3 *}$, Liliane Marcia Mertz ${ }^{4}$, Ubirajara Russi Nunes ${ }^{3}$ e \\ Gerusa Massuquini Conceição ${ }^{2}$
}

\begin{abstract}
RESUMO - Na produção de sementes de trigo diversos fatores (bióticos e abióticos) podem alterar o rendimento e a qualidade de sementes, dentre esses cita-se o estabelecimento adequado das plantas no campo. Dessa forma, objetivouse com esse trabalho verificar o efeito da redução da população de trigo de forma aleatória no rendimento e na qualidade fisiológica das sementes produzidas. O estudo foi realizado nas cultivares Horizonte, Marfim, Mirante e Quartzo. Anteriormente à fase do afilhamento, procedeu-se a retirada de plantas de maneira aleatória nas intensidades de 0;20; 40 e $60 \%$ em relação à população original (350 plantas por metro quadrado). Após a colheita, avaliou-se o rendimento e a qualidade das sementes produzidas, por meio dos testes de germinação, envelhecimento acelerado, condutividade elétrica massal e massa de mil sementes. Verificou-se que as cultivares apresentam desempenho diferente quando submetidas a reduções aleatórias de plantas demonstrando capacidades distintas em compensar eventuais falhas na semeadura. A resposta para rendimento de trigo em função da redução aleatória na população de plantas varia conforme o genótipo utilizado. Quanto à qualidade das sementes produzidas, reduções aleatória de plantas de trigo afetam negativamente a qualidade fisiológica das sementes.
\end{abstract}

Palavras-chave: Triticum aestivum L. Sementes-rendimento. Germinação.

\begin{abstract}
In the production of wheat seeds several factors (both biotic and abiotic) can alter the yield and quality of the seeds, among these is the appropriate establishment of the plants in the field. The aim of this work therefore, was to investigate the effect of randomly reducing the wheat population on yield and physiological quality of the seeds produced. The study was carried out on the cultivars, Fundacep Horizonte, Marfim, Mirante and Quartzo. Prior to the tillering stage, plants were removed at random at levels of $0 ; 20 ; 40$ and $60 \%$ of the original population (350 plants per square metre). After harvest, the yield and quality of the seeds produced were evaluated by testing germination, accelerated ageing, mass electrical conductivity and thousand-seed weight. It was found that the cultivars perform differently when subjected to random plant reduction, demonstrating different capabilities in compensating for any flaw in seeding. The response for wheat yield due to the random reduction in plant population varies by genotype. As for the quality of the seeds produced, random reductions of wheat plants negatively affect the physiological quality of the seeds.
\end{abstract}

Key words: Triticum aestivum L. Spatial distribution of plants. Germination.

\footnotetext{
*Autor para correspondência

'Recebido para publicação em 15/03/2012; aprovado em 14/04/2013

Pesquisa Financiada pela Universidade Federal de Santa Maria

${ }^{2}$ Programa de Pós-Graduação em Agronomia, Departamento de Fitotecnia, Universidade Federal de Santa Maria/UFSM, Santa Maria-RS, Brasil,apaulabarbieri@yahoo.com.br, g.massukini@hotmail.com

${ }^{3}$ Departamento de Fitotecnia, Universidade Federal de Santa Maria/UFSM, Santa Maria-RS, Brasil, martin.ufsm@gmail.com, russinunes@ yahoo.com.br

${ }^{4}$ Empresa Brasileira de Pesquisa Agropecuária/EMBRAPA-Soja, Londrina-PR, Brasil, lilianemertz@ yahoo.com.br
} 


\section{INTRODUÇÃO}

O trigo é o segundo cereal mais cultivado em volume no mundo, 690 milhões de toneladas (UNITED STATES DEPARTMENT OF AGRICULTURE, 2011) e um dos mais importantes cultivados no Brasil durante o período hibernal 5,8 milhões de toneladas em uma área aproximada de 2,1 milhões de hectares (COMPANHIA NACIONAL DE ABASTECIMENTO, 2012). Atualmente, há o interesse sócio-econômico em aumentar a produção de trigo no país, pois além do atendimento à demanda nacional, seu cultivo melhora as condições do solo e fornece palhada para as culturas de verão, como soja e milho.

Devido a essa necessidade de incrementos no rendimento, surge a demanda pela produção e obtenção de sementes de elevada qualidade (LIMA; MEDINA; FANAN, 2006). Sementes de elevada qualidade apresentam maior velocidade nos processos metabólicos, propiciando emissão mais rápida e uniforme da raiz primária no processo de germinação e maior taxa de crescimento, produzindo plântulas com maior tamanho inicial o que se refle em maior crescimento e maior rendimento de grãos (MIELEZRSKI et al., 2008; MUNIZZI et al., 2010). Considerando que a taxa de utilização de sementes certificadas de trigo no Brasil é de aproximadamente $70 \%$, é necessário anualmente, uma quantidade equivalente a $203 \mathrm{mil}$ toneladas de sementes (ASSOCIAÇÃO BRASILEIRA DE SEMENTES E MUDAS, 2011), movimentando em torno de 100 milhões de dólares.

Dentre os fatores que interferem na produção de sementes de trigo pode-se citar o adequado preparo do solo (YOKOYAMA; SILVEIRA; STONE, 2002), a operação de semeadura (densidade e profundidade) (VALÉRIO et al., 2008), a utilização correta de insumos (BRAZ et al., 2006) e de sementes de elevada qualidade (VAZQUEZ; CARVALHO; BORBA, 2008), a escolha da cultivar (COVENTRY et al., 2011) e as condições climáticas (VIGANÓ et al., 2010). Além disso, o estabelecimento de uma população adequada de plantas de forma rápida e uniforme no início do desenvolvimento da cultura é de suma importância para obtenção de resultados satisfatórios (quantidade e qualidade). $\mathrm{O}$ número de plantas altera a produção de fitomassa seca de parte aérea e produção de afilhos, que altera sensivelmente a produção da cultura (MARTIN et al., 2010).

Frequentemente observa-se que ocorrem reduções na população de plantas devido a danos causados no início do desenvolvimento da cultura como a ocorrência de insetos de solo (SANTOS; ÁVILA, 2009), estresses abióticos (FUMIS; PEDRAS, 2002), qualidade e disponibilidade de luz (OZTURK, 2006) e condições físicas e químicas do solo (STONE et al., 2002), a baixa qualidade fisiológica das sementes também é um fator que reduz o estande final de plantas (LIMA; MEDINA;FANAN, 2006). Além da redução do estande, existe a alteração da distribuição espacial das plantas dentro do dossel, isso pode proporcionar maior competição por recursos do meio em um conjunto de plantas mais próximas e menor competição em outras plantas mais afastadas. Com isso, pode haver alteração nas relações de fonte e dreno, fazendo com que exista uma dinâmica diferenciada na emissão de afilhos férteis, bem como nas suas sementes produzidas (VALÉRIO et al., 2008).

Pela capacidade de emissão de afilhos férteis, o trigo apresenta a propriedade de preencher os espaços vazios na lavoura, compensando possíveis falhas na semeadura (ZAGONEL et al., 2002). Porém, em alguns casos ocorre formação de afilhos inférteis e dessa maneira, o potencial de afilhamento não será expresso em rendimento de sementes (VALÉRIO et al., 2008).

Dessa forma, objetivou-se com esse trabalho, verificar o efeito da redução aleatória de plantas de trigo no rendimento e na qualidade fisiológica das sementes produzidas.

\section{MATERIAL E MÉTODOS}

O estudo foi conduzido na área experimental do Departamento de Fitotecnia, da Universidade Federal de Santa Maria, no município de Santa Maria - RS, região climática da Depressão Central, a uma altitude de 116 $\mathrm{m}$, latitude $29^{\circ} 42^{\prime} 24^{\prime \prime} \mathrm{S}$ e longitude $53^{\circ} 48^{\prime} 42^{\prime \prime} \mathrm{W}$. O clima da região, segundo a classificação de KÖEPPEN (MORENO, 1961) é do tipo Cfa. O solo pertence à Unidade de Mapeamento São Pedro, sendo classificado no Sistema Brasileiro de Classificação de Solos como Argissolo Vermelho Distrófico Arênico (EMPRESA BRASILEIRA DE PESQUISA AGROPECUÁRIA, 2006).

O experimento foi instalado sobre restos da palhada da soja (safra 2010/2011). O controle de plantas daninhas foi realizado no dia anterior à semeadura (9/06/2011), com o herbicida gliphosate (Roundup WG ${ }^{\circledR}$ ) na dose de $0,8 \mathrm{~kg} \mathrm{ha}^{-1}$, seguindo as recomendações da Reunião da Comissão Brasileira de Pesquisa de Trigo e Triticale (2011) para o controle de plantas daninhas, insetos praga e doenças. As sementes foram tratadas com inseticida imidacloprido $150 \mathrm{~g} . \mathrm{L}^{-1}+$ tiodiocarbe $450 \mathrm{~g} . \mathrm{L}^{-1}$ $\left(\right.$ Cropstar $\left.^{\circledast}\right)$, na dosagem de $0,3 \mathrm{~L}$ de produto para $100 \mathrm{~kg}$ de sementes e também com fungicida triazol 150 g.L $\mathrm{L}^{-1}$ (Baytan $\mathrm{SC}^{\circledR}$ ) na dosagem de $0,2 \mathrm{~L}$ de produto comercial para $100 \mathrm{~kg}$ de sementes. A semeadura ocorreu no dia $10 \mathrm{de}$ junho, e a emergência, sete dias após a semeadura, quando 
se verificou pelo menos $50 \%$ das plântulas emergidas. Utilizou-se a densidade de semeadura de 350 plantas $\mathrm{m}^{-2}$, com espaçamento entre fileiras de $0,20 \mathrm{~m}$, sendo esta realizada manualmente. A adubação foi realizada de acordo com resultados da análise de solo, utilizou-se na base $350 \mathrm{~kg} \mathrm{ha}^{-1}$ de fertilizante na formulação 5-20-20. A adubação de cobertura foi realizada com aplicação de nitrogênio (uréia, $45 \%$ de $\mathrm{N}$ ) no estádio de afilhamento pleno (15 de julho de 2011).

À campo, o delineamento experimental foi $o$ de blocos completamente casualizados com quatro repetições e os tratamentos foram organizados em um fatorial (quatro cultivares e quatro reduções de plantas). As cultivares de trigo utilizadas foram Fundacep Horizonte, Marfim, Mirante e Quartzo e o número de plantas inicial de toda a parcela foi reduzido em $0 ; 20 ; 40$ e 60\%, para cada uma das cultivares. As parcelas experimentais possuíam 11 fileiras, de quatro metros de comprimento, espaçadas $20 \mathrm{~cm}$ entre si. A área útil foi de $4,4 \mathrm{~m}^{2}$. Nas análises de laboratório, utilizou-se delineamento inteiramente casualizado, com 16 repetições, pois se considerou que não haveria variabilidade laboratorial, antes ou depois da instalação do experimento no laboratório.

Para a retirada aleatória das plantas da parcela, considerou-se inicialmente o número total de plantas em cada uma das fileiras (11), onde cada planta recebeu um número ordinal de 1 a n. Posteriormente, gerou-se para cada uma das fileiras listas de números aleatórios com distribuição uniforme \{528 listas [11 fileiras x 4 cultivares x 3 reduções de plantas (20\%; $40 \%$ e $60 \%)$ x 4 blocos] $\}$, correspondente aos números das plantas que deveriam ser retiradas do campo, segundo as reduções propostas. E então, procedeu-se a retirada manual de cada uma das plantas sorteadas na listagem. As plantas foram retiradas no início do período de afilhamento.

A colheita foi realizada manualmente após a maturidade fisiológica das sementes, colhendo-se a área útil da parcela. Realizou-se a pesagem e a verificação da umidade da massa de sementes em cada uma das parcelas, posteriormente os dados foram extrapolados para rendimento de sementes por hectare $\left(\mathrm{kg} \mathrm{ha}^{-1}\right)$ e ajustando-se os dados de rendimento para $13 \%$ de umidade, permitindo-se assim a comparação entre os resultados dos tratamentos.

Posteriormente, as amostras foram levadas ao Laboratório Didático e de Pesquisa em Sementes do Departamento de Fitotecnia da Universidade Federal de Santa Maria, para a realização dos seguintes testes para verificar a qualidade de sementes: (i) Germinação: foram utilizadas 16 repetições de 50 sementes, semeadas em rolos de papel umedecidos a 2,5 vezes a massa do papel seco e mantidos em germinador regulado a $20{ }^{\circ} \mathrm{C}$. As avaliações foram realizadas aos quatro e oito dias, após início do teste, conforme as Regras para Análises de Sementes - RAS (BRASIL, 2009), sendo os resultados expressos em porcentagem de plântulas normais; (ii) Teste de envelhecimento acelerado: conduzido em caixa plástica tipo gerbox, onde foram adicionados $40 \mathrm{~mL}$ de água e colocada uma tela de arame galvanizado, sobre a qual foram postas as sementes, impedindo o contato destas com a água. As caixas foram fechadas, mantendo a umidade relativa em $100 \%$, levadas a uma estufa incubadora por um período de 60 horas, a uma temperatura de $42{ }^{\circ} \mathrm{C}$, de acordo com recomendação de Marcos Filho (1999). Em seguida procedeu-se a semeadura conforme descrito no teste de germinação, com 16 repetições de 50 sementes por tratamento, sendo as avaliações efetuadas aos quatro dias após a instalação do teste; (iii) Condutividade elétrica massal: utilizaram-se 16 repetições de 50 sementes, de massa conhecida, por lote, imersas em $75 \mathrm{~mL}$ de água destilada deionizada, a $20^{\circ} \mathrm{C}$. Após 24 horas foi realizada a leitura da condutividade elétrica da solução de imersão e os resultados expressos em $\mu \mathrm{S} \mathrm{cm}^{-1} \mathrm{~g}^{-1}$ de semente e (iv) Massa de 1000 sementes: conduzido com 16 repetições de oito sub-amostras de 100 sementes conforme as RAS (BRASIL, 2009).

Os dados foram submetidos à análise de variância e posteriormente testaram-se os graus da equação (até terceiro grau), ajustou-se a equação de regressão de maior grau significativo, pelo teste F, em nível de 5\% de erro. Para essas análises utilizou-se o software Sisvar (FERREIRA, 2008).

\section{RESULTADOS E DISCUSSÃO}

De acordo com a análise de variância (Tabela 1, Tabela 2 e Tabela 3), para todas as características avaliadas, observou-se interação significativa entre cultivar $\mathrm{x}$ redução aleatória na população de plantas. Dessa forma, cada cultivar possui um desempenho distinto quando submetido à redução aleatória de plantas.

Para a característica rendimento de sementes, observou-se efeito significativo apenas para a cultivar Mirante, sendo que, reduções acentuadas na população de plantas resultaram em diminuição linear no rendimento demonstrando que essa cultivar apresentou menor capacidade de compensação em relação às demais (Figura 1a). Embora o trigo possua a capacidade de compensar alterações na população de plantas por meio da emissão de afilhos, a capacidade de emissão de afilhos totais e afilhos férteis é variável entre os genótipos, conforme estudos com as culturas da aveia (ALVES et al., 2004) e trigo (VALÉRIO et al., 2008). Esse fator pode explicar as diferenças no comportamento das diferentes cultivares para a variável rendimento. 
Tabela 1 - Análise de variância contendo as fontes de variação (FV), os graus de liberdade (GL), os quadrados médios (QM), estatística $\mathrm{F}(\mathrm{F})$, probabilidade de rejeitar a hipótese de nulidade $(\mathrm{F} \geq \mathrm{Fc})$, para a escolha do grau da equação, probabilidade de rejeitar a hipótese da nulidade pelo teste $\mathrm{T}(\mathrm{PR}>\mathrm{T})$, média e coeficiente de variação para a variável rendimento de sementes

\begin{tabular}{lcccc}
\hline \multicolumn{1}{c}{ FV } & \multicolumn{3}{c}{ Rendimento de Sementes $\left(\mathrm{kg} \mathrm{ha}^{-1}\right)$} \\
\hline Bloco & GL & QM & F & F $\geq$ Fc \\
Cultivares (a) & 3 & 45640,01 & 0,319 & 0,81 \\
Redução (d) & 3 & 394978,40 & 2,760 & 0,053 \\
a x d & 3 & 217958,56 & 1,523 & 0,2215 \\
Erro & 9 & 375787,54 & 2,626 & 0,015 \\
& 45 & 143119,07 & & PF $>\mathrm{F}$ \\
Primeiro Grau & & QM & 1,88 & 0,176 \\
Segundo Grau & & 1,25 & 0,268 \\
Terceiro Grau & & 179714,52 & 1,42 & 0,239 \\
\hline
\end{tabular}

\begin{tabular}{lcc}
\hline & Cultivar Horizonte \\
Média & Cultivar Quartzo \\
& 2658,85 \\
\hline Média & Cultivar Mirante \\
\hline \multicolumn{3}{c}{ PR $>$ T } \\
\hline Coef. Linear & Estimativa & 0,0000 \\
X1 & 3388,97 & 0,0029 \\
\hline & $-13,3277$ & Cultivar Marfim \\
Média & \multicolumn{3}{c}{2654,59} \\
\hline Média Geral & 2761,88 \\
CV & \multicolumn{3}{c}{13,70} \\
\hline
\end{tabular}

Tabela 2 - Análise de variância contendo as fontes de variação (FV), os graus de liberdade (GL), os quadrados médios (QM), estatística $\mathrm{F}(\mathrm{F})$, probabilidade de rejeitar a hipótese de nulidade $(\mathrm{F} \geq \mathrm{Fc})$, para a escolha do grau da equação, probabilidade de rejeitar a hipótese da nulidade pelo teste $\mathrm{T}(\mathrm{PR}>\mathrm{T})$, média e coeficiente de variação, para as variáveis germinação e massa de mil sementes

\begin{tabular}{|c|c|c|c|c|c|c|c|}
\hline \multirow{2}{*}{ FV } & \multirow{2}{*}{ GL } & \multicolumn{3}{|c|}{ Germinação (\%) } & \multicolumn{3}{|c|}{ Massa de mil sementes (g) } \\
\hline & & $\mathrm{QM}$ & $\mathrm{F}$ & $\mathrm{F} \geq \mathrm{Fc}$ & QM & $\mathrm{F}$ & $\mathrm{F} \geq \mathrm{Fc}$ \\
\hline Cultivares (a) & 3 & 1639,93 & 16,26 & 0,00 & 1,31 & 19,98 & 0,0 \\
\hline Redução (d) & 3 & 732,84 & 7,27 & 0,0001 & 0,19 & 2,97 & 0,032 \\
\hline $\mathrm{a} \times \mathrm{d}$ & 9 & 372,95 & 3,69 & 0,0002 & 0,21 & 3,17 & 0,001 \\
\hline \multirow[t]{2}{*}{ Erro } & 240 & 100,84 & & & 0,066 & & \\
\hline & & QM & Valor F & $\mathrm{PF}>\mathrm{F}$ & QM & Valor F & $\mathrm{PF}>\mathrm{F}$ \\
\hline Primeiro Grau & & 2047,78 & 30,31 & 0,00 & 1,51 & 2,31 & 0,13 \\
\hline Segundo Grau & & 4,25 & 0,04 & 0,84 & 2,60 & 3,96 & 0,04 \\
\hline \multirow[t]{3}{*}{ Terceiro Grau } & & 146,47 & 1,45 & 0,23 & 1,74 & 2,65 & 0,10 \\
\hline & & \multicolumn{6}{|c|}{ Cultivar Horizonte } \\
\hline & & Estimativa & $\mathrm{PR}>\mathrm{T}$ & & & Estimativa & $\mathrm{PR}>\mathrm{T}$ \\
\hline Coef. linear & & 82,725 & 0,0000 & & & 27,51 & 0,0000 \\
\hline $\mathrm{X} 1$ & & 0,2784 & 0,1577 & & & 0,203 & 0,0001 \\
\hline $\mathrm{X} 2$ & & $-0,0076$ & 0,0165 & & & $-0,003$ & 0,0001 \\
\hline
\end{tabular}


Continuação Tabela 2

\begin{tabular}{|c|c|c|c|c|c|}
\hline & \multicolumn{5}{|c|}{ Cultivar Quartzo } \\
\hline & Estimativa & $\mathrm{PR}>\mathrm{T}$ & & Média & \\
\hline Coef. linear & 88,046 & 0,0000 & & 31,67 & \\
\hline $\mathrm{X} 1$ & $-0,6676$ & 0,0008 & & & \\
\hline \multirow[t]{3}{*}{$\mathrm{X} 2$} & 0,0092 & 0,0035 & & & \\
\hline & \multicolumn{5}{|c|}{ Cultivar Mirante } \\
\hline & Estimativa & $\mathrm{PR}>\mathrm{T}$ & & Estimativa & $\mathrm{PR}>\mathrm{T}$ \\
\hline Coef. linear & 94,027 & 0,0000 & & 34,216 & 0,0000 \\
\hline \multirow[t]{2}{*}{$\mathrm{X} 1$} & $-0,1469$ & 0,0094 & & $-0,054$ & 0,0002 \\
\hline & \multicolumn{5}{|c|}{ Cultivar Marfim } \\
\hline Média & 89,34 & & 30,62 & & \\
\hline $\mathrm{CV}$ & 11,80 & & 8,27 & & \\
\hline Média & 85,10 & & 31,03 & & \\
\hline
\end{tabular}

Tabela 3 - Análise de variância contendo as fontes de variação (FV), os graus de liberdade (GL), os quadrados médios (QM), estatística F (F), probabilidade de rejeitar a hipótese de nulidade $(\mathrm{F} \geq \mathrm{Fc})$, para a escolha do grau da equação, probabilidade de rejeitar a hipótese da nulidade pelo teste $\mathrm{T}(\mathrm{PR}>\mathrm{T})$, média e coeficiente de variação, para as variáveis envelhecimento acelerado e condutividade elétrica massal

\begin{tabular}{|c|c|c|c|c|c|c|c|}
\hline & & \multicolumn{3}{|c|}{ Envelhecimento acelerado (\%) } & \multicolumn{3}{|c|}{ Condutividade elétrica massal $\left(\mu \mathrm{S} \mathrm{cm}^{-1} \mathrm{~g}^{-1}\right)$} \\
\hline & & QM & $\mathrm{F}$ & $\mathrm{F} \geq \mathrm{Fc}$ & QM & $\mathrm{F}$ & $\mathrm{F} \geq \mathrm{Fc}$ \\
\hline Cultivares(a) & 3 & 263,04 & 7,61 & 0,0001 & 2083,97 & 121,90 & 0,00 \\
\hline Redução (d) & 3 & 29,29 & 0,85 & 0,4686 & 8,81 & 0,51 & 0,67 \\
\hline $\mathrm{a} \times \mathrm{d}$ & 9 & 214,55 & 6,21 & 0,000 & 30,23 & 1,77 & 0,049 \\
\hline \multirow[t]{2}{*}{ Erro } & 240 & 34,53 & & & 17,09 & & \\
\hline & & QM & Valor F & $\mathrm{PF}>\mathrm{F}$ & QM & Valor F & $\mathrm{PF}>\mathrm{F}$ \\
\hline Primeiro Grau & 10,51 & 0,304 & 0,582 & 8,01 & 0,47 & 0,494 & \\
\hline Segundo Grau & 76,56 & 2,217 & 0,138 & 3,35 & 0,19 & 0,658 & \\
\hline Terceiro Grau & 0,80 & 0,023 & 0,879 & 15,07 & 0,88 & 0,349 & \\
\hline \multicolumn{8}{|c|}{ Cultivar Horizonte } \\
\hline Média & & 88,53 & & & 27,89 & & \\
\hline \multicolumn{8}{|c|}{ Cultivar Quartzo } \\
\hline & & Estimativa & $\mathrm{PR}>\mathrm{T}$ & & & Média & \\
\hline Coef. linear & & 90,6090 & 0,0000 & & & 29,16 & \\
\hline $\mathrm{X} 1$ & & $-0,0693$ & 0,0357 & & & & \\
\hline \multicolumn{8}{|c|}{ Cultivar Mirante } \\
\hline & & Estimativa & $\mathrm{PR}>\mathrm{T}$ & & & Estimativa & $\mathrm{PR}>\mathrm{T}$ \\
\hline Coef. linear & & 93,9940 & 0,0000 & & & 21,753 & 0,0000 \\
\hline $\mathrm{X} 1$ & & 0,0906 & 0,0004 & & & 0,2159 & 0,0081 \\
\hline $\mathrm{X} 2$ & & & & & & $-0,0038$ & 0,0035 \\
\hline \multicolumn{8}{|c|}{ Cultivar Marfim } \\
\hline & & Estimativa & $\mathrm{PR}>\mathrm{T}$ & & & Média & \\
\hline Coef. linear & & 85,013 & 0,0000 & & & 16,60 & \\
\hline $\mathrm{X} 1$ & & 0,584 & 0,0000 & & & & \\
\hline $\mathrm{X} 2$ & & $-0,0084$ & 0,0000 & & & & \\
\hline Média Geral & & 91,25 & & & 17,13 & & \\
\hline $\mathrm{CV}$ & & 6,44 & & & 24,14 & & \\
\hline
\end{tabular}


Figura 1 - Rendimento de sementes (RS, $\mathrm{kg} \mathrm{ha}^{-1}$ ) (a) e Massa de mil sementes (MMS, g) (b) em quatro cultivares de trigo, submetidas à redução aleatória do estande de plantas (RE, \%). Santa Maria - RS, 2012. ${ }^{(*)}$ Significativo pelo teste F ao nível de $5 \%(\mathrm{P}<0,05)$
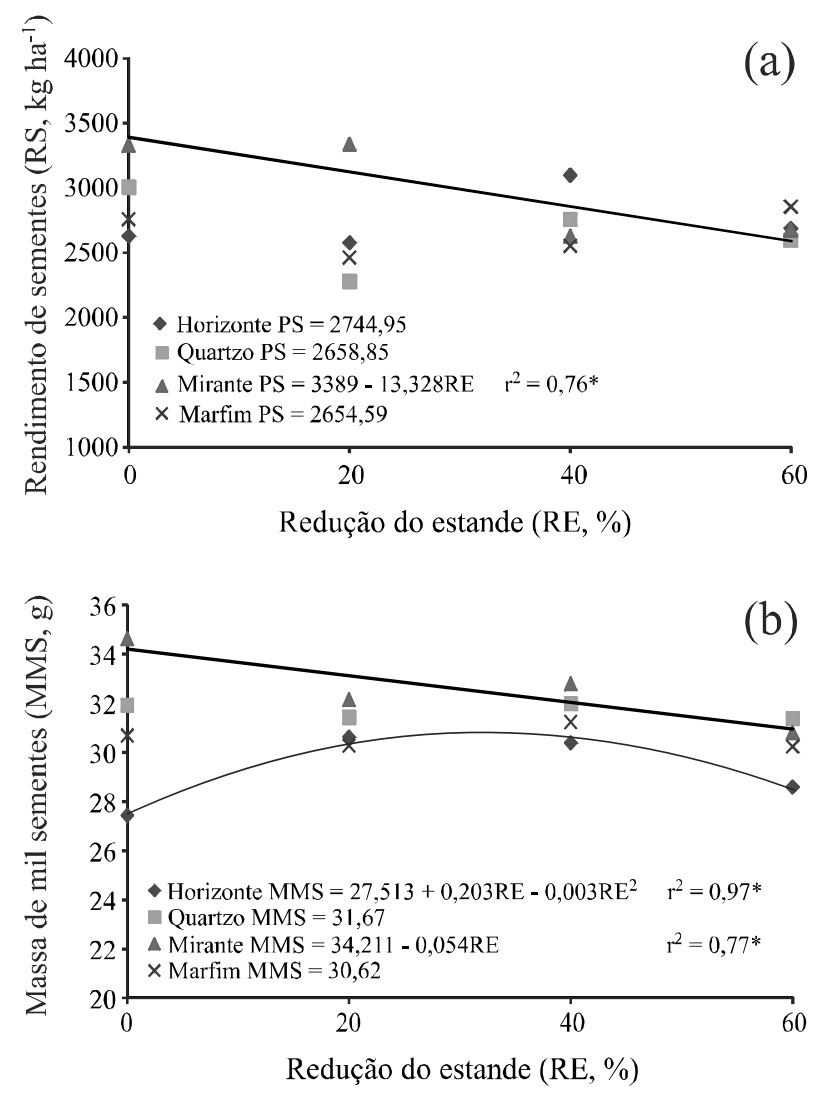

Com relação à massa de mil sementes (Figura 1b), as cultivares Mirante e Horizonte tiveram redução na massa de mil sementes nos tratamentos onde a redução de plantas foi mais drástica. O comportamento esperado era que populações com maior redução no número de plantas apresentassem maior massa de mil sementes, devido à menor competição entre plantas, favorecendo a translocação de fotoassimilados para as sementes, resultando em maior acúmulo de massa seca.

Os resultados desse estudo podem ser devido ao fato que reduções acentuadas na população de plantas levam a uma maior necessidade de compensação por meio da emissão de afilhos. O rendimento dos afilhos está relacionada com a taxa de desenvolvimento destes em relação ao colmo principal (POLETTO et al., 2011), sendo que a competitividade entre plantas acelera o desenvolvimento do colmo principal em detrimento de seus afilhos. Sendo assim, genótipos de trigo com menor capacidade de emissão de afilhos produzem uma maior fertilidade de espiguetas e maior massa de grãos por planta (MOTZO et al., 2004).

Em relação à qualidade fisiológica das sementes, de acordo com os resultados do Teste de germinação (Figura 2a), nas cultivares Horizonte e Mirante, observa-se que a porcentagem de plântulas normais no teste de germinação foi menor em tratamentos onde houve a redução da população de plantas. Para a cultivar Marfim não se observou efeito significativo, enquanto que a cultivar Quartzo apresentou oscilação da germinação com o aumento da intensidade de redução do estande.

Em relação ao vigor das sementes, medido pelo Teste de envelhecimento acelerado (Figura 2b) observou-se efeito significativo para as cultivares Mirante, Quartzo e Marfim, com redução da qualidade das sementes à medida que diminui a população. Essas alterações na qualidade fisiológica podem estar relacionadas às variações observadas na massa de mil sementes, pois sementes de menor tamanho ou menor massa de mil sementes podem apresentar qualidade fisiológica inferior.

As informações existentes sobre trabalhos que correlacionam tamanho e massa de mil sementes com qualidade fisiológica são ambíguas. De acordo com McDonald Junior (1975), tamanho de sementes é um fator que tem influencia sobre o vigor, sendo que sementes de maior tamanho possuem maior qualidade fisiológica. Em sementes de canola, Ávila et al. (2005), não verificaram relação entre massa de mil sementes e vigor. Esse mesmo comportamento foi observado para sementes de milho em estudos conduzidos por Andrade et al. (1997). Sementes de girassol com maior massa de mil sementes não apresentaram relação com vigor em avaliações realizadas imediatamente após a colheita, por outro lado, após seis meses de armazenamento sementes menores apresentaram reduções no vigor (AGUIAR et al., 2001).

Em relação ao Teste de condutividade elétrica (Figura 2c), houve efeito significativo apenas para a cultivar Mirante, a qual apresentou comportamento quadrático, mostrando oscilação no valor de condutividade elétrica à medida em que ocorre a redução da população de plantas. Esse resultado não permite fazer uma associação entre população de plantas e vigor de sementes medido pela condutividade elétrica (Figura 2a e 2b). Dessa forma, no presente trabalho, o teste de condutividade elétrica não foi eficiente em detectar diferenças de qualidade entre os diferentes lotes de sementes de trigo, o que ressalta a importância de se utilizar mais de um teste de vigor 
Figura 2 - Teste de germinação (\%) (a), Teste de envelhecimento acelerado (\%) (b) e Condutividade elétrica massal (CEM, $\mu \mathrm{S} \mathrm{cm}^{-1} \mathrm{~g}^{-1}$ ) (c) em quatro cultivares de trigo, submetidas a redução aleatória do estande de plantas (RE, \%). Santa Maria - RS, 2012. ${ }^{(*)}$ Significativo pelo teste F ao nível de $5 \%(\mathrm{P}<0,05)$
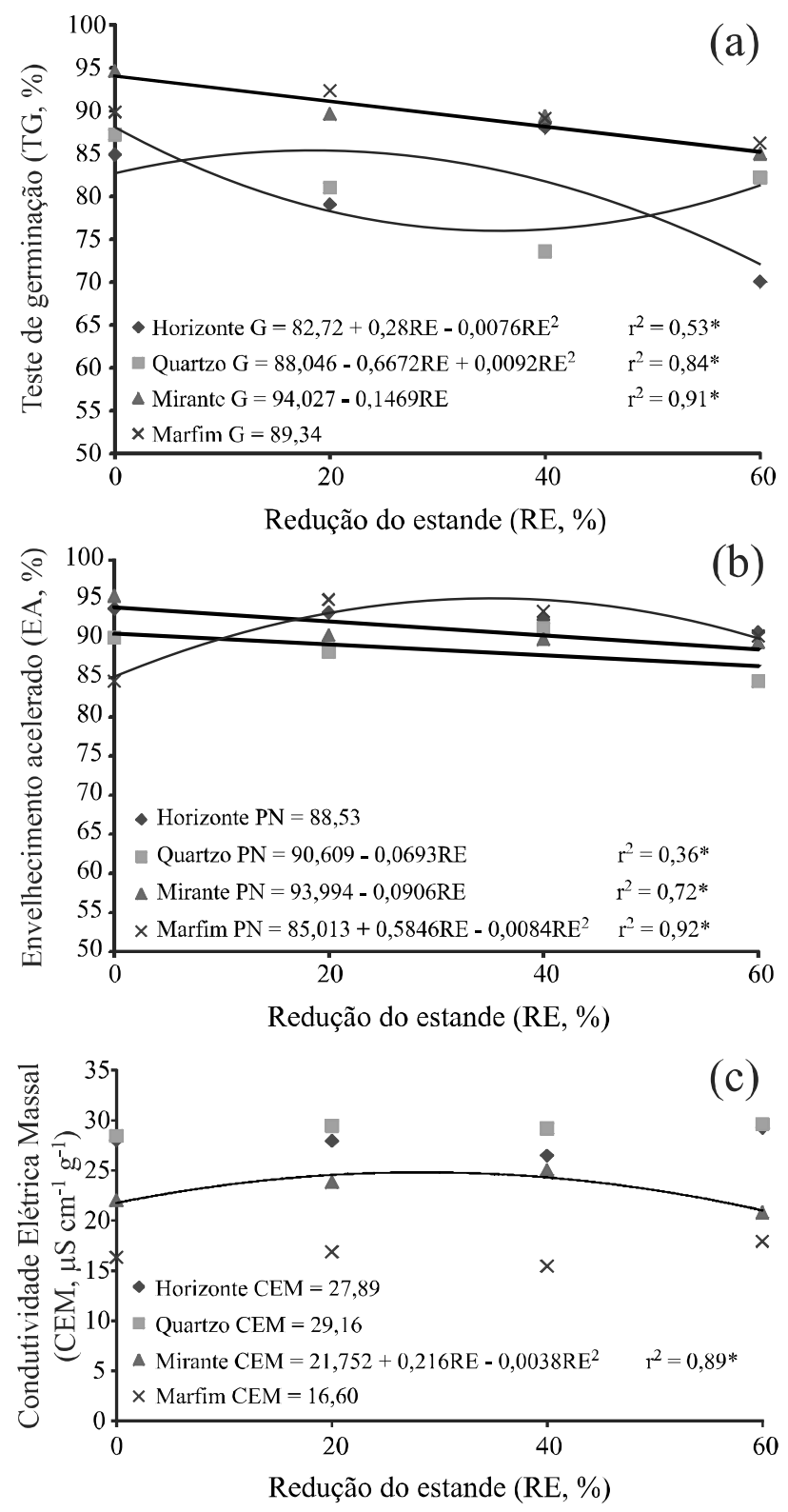

para uma avaliação segura da qualidade das sementes. Já o teste de envelhecimento acelerado, apresentou comportamento semelhante ao observado no teste padrão de germinação o que corrobora com dados obtidos por (FANAN et al., 2006), os quais afirmam que o envelhecimento acelerado é adequado para avaliação do vigor de sementes de trigo.

\section{CONCLUSÕES}

1. A resposta para rendimento de trigo em função da redução aleatória na população de plantas varia conforme o genótipo utilizado;

2. Quanto à qualidade das sementes produzidas, reduções aleatórias de plantas de trigo afetam negativamente a qualidade fisiológica das sementes.

\section{REFERÊNCIAS}

ASSOCIAÇÃO BRASILEIRA DE SEMENTES E MUDAS. Anuário 2011: Agricultura sem fronteiras. 2011. 86 p.

AGUIAR, R. H. et al. Qualidade física, fisiológica e sanitária de sementes de girassol de diferentes tamanhos. Revista Brasileira de Sementes, v. 23, n. 1, p. 134-139, 2001.

ALVES, A. C. et al. Emissão do afilho do coleóptilo em genótipos de aveia e em diferentes condições de estresses e manejo. Ciência Rural, v. 34, n. 2, p. 385-391, 2004.

ANDRADE, R. V. et al. Efeito da forma e do tamanho da semente no desempenho no campo de dois genótipos de milho. Revista Brasileira de Sementes, v. 19, n. 1, p.62-65, 1997.

ÁVILA, M. R. et al. Testes de laboratório em sementes de canola e a correlação com a emergência das plântulas em campo. Revista Brasileira de Sementes, v. 27, n. 1, p. 62-70, 2005.

BRASIL. Ministério da Agricultura e Reforma Agrária. Regras para análise de sementes. Brasília, 2009. 399 p.

BRAZ, A. J. B. P. et al. Adubação nitrogenada em cobertura na cultura do trigo em sistema de plantio direto após diferentes culturas. Ciência Agrotécnica, v. 30, n. 2, p. 193198, 2006.

COMPANHIA NACIONAL DE ABASTECIMENTO. Acompanhamento de safra brasileira: grãos, quarto levantamento, safra 2011/2012. Brasília, 2012. 38 p.

COVENTRY, D. R. et al. Wheat quality and productivity as affected by varieties and sowing time in Haryana, India. Field Crops Research, v. 123, n. 3, p. 214-225, 201

EMPRESA BRASILEIRA DE PESQUISA AGROPECUÁRIA. Sistema brasileiro de classificação de solos. 2 . ed. Rio de Janeiro: Embrapa Solos, 2006. 306 p.

FANAN, S. et al. Avaliação do vigor de sementes de trigo pelos testes de envelhecimento acelerado e de frio. Revista Brasileira de Sementes, v. 28, n. 2, p. 152-158, 2006.

FERREIRA, D. F. Sisvar: um programa para análises e ensino de estatística. Revista Symposium, v. 6, p. 36-41, 2008.

FUMIS, T. F.; PEDRAS, J. F. Variação nos níveis de prolina, diamina e poliaminas em cultivares de trigo submetidas a déficits hídricos. Pesquisa Agropecuária Brasileira, v. 37, n. 4, p. 75-79, 2002.

MARCOS FILHO, J. Teste de envelhecimento acelerado. In: KRZYZANOWSKI, F. C.; VIEIRA, R. D.; FRANÇA NETO, 
J. B. (Ed.). Vigor de sementes: conceitos e testes. Londrina: ABRATES, 1999. 218 p. cap. 3, p. 1-24.

LIMA, T. C.; MEDINA, P. F.; FANAN, S. Avaliação do vigor de sementes de trigo pelo teste de envelhecimento acelerado. Revista Brasileira de Sementes, v. 28, n. 1, p. 106-113, 2006.

MARTIN, T. N. et al. Fitomorfologia e produção de cultivares de trigo duplo propósito em diferentes manejos de corte e densidades de semeadura. Ciência Rural, v. 40, n. 8, p. 1695-1701, 2010.

MCDONALD JUNIOR, M. B. A review and evaluation of seed vigor tests. Proceeding of Association of Official Seed Analysts, v. 65, n. 1, p.109-139, 1975.

MIELEZRSKI, F. et al. Desempenho em campo de plantas isoladas de arroz híbrido em função da qualidade fisiológica das sementes. Revista Brasileira de Sementes, v. 30, n. 3, p. 139-144, 2008.

MORENO, J. A. Clima do Rio Grande do Sul. Porto Alegre: Secretaria da Agricultura, 1961. 42 p.

MOTZO, R. et al. Expression of a tiller inhibitor gene in the progenies of interspecific crosses Triticum aestivum L. x T. turgidum subsp. durum. Field Crop Research, v. 85, n. 1, p. 15-20, 2004.

MUNIZZI, A. et al. Qualidade de sementes de quatro cultivares de soja, colhidas em dois locais no estado de Mato Grosso do Sul. Revista Brasileira de Sementes, v. 32, n. 1, p. 176-185, 2010.

OZTURK, A. et al. Growth and yield response of facultative wheat to winter sowing, freezing sowing and spring sowing at different seeding rates. Journal of Agronomy and Crop Science, v. 192, p. 10-16, 2006.

POLETTO, N. et al. Padrão de afilhamento em arroz afetado pela presença dos íons amônio e nitrato. Bragantia, v. 70, n. 1, p. 96-103, 2011.
REUNIÃO DA COMISSÃO BRASILEIRA DE PESQUISA DE TRIGO E TRITICALE, 4., 2011, Cascavel, PR. Anais... Cascavel, 2011. $171 \mathrm{p}$.

SANTOS, V.; ÁVILA, C. J. Aspectos Biológicos e Comportamentais de Liogenys suturalis Blanchard (Coleoptera: Melolonthidae) no Mato Grosso do Sul. Neotropical Entomology, v. 38, n. 6, p. 734-739, 2009.

STONE, L. F. et al. Compactação do solo na cultura do feijoeiro. I: Efeito nas propriedades físico-hídricas do solo. Revista Brasileira de Engenharia Agrícola e Ambiental, v. 6, n. 2, p. 207-212, 2002.

UNITED STATES DEPARTMENT OF AGRICULTURE. Brazil Corn: Estimated yield increases following good rainfall. Disponível em: <www.fas.usda.gov/psdonline/circulars/ production.pdf > Acesso em: 13 ago. 2011.

VALÉRIO, I. P. et al. Desenvolvimento de afilhos e componentes do rendimento em genótipos de trigo sob diferentes densidades de semeadura. Pesquisa Agropecuária Brasileira, v. 43, n. 3, p. 319-326, 2008.

VAZQUEZ, G. H.; CARVALHO, N. M.; BORBA, M. M. Z. Redução na população de plantas sobre a produtividade e a qualidade fisiológica da semente de soja. Revista Brasileira de Sementes, v. 30, n. 2, p. 1-11, 2008.

VIGANÓ, J. et al. Qualidade fisiológica de sementes de trigo em resposta aos efeitos de anos e épocas de semeadura. Revista Brasileira de Sementes, v. 32, n. 3, p. 86-96, 2010.

YOKOYAMA, L. P.; SILVEIRA, P. M.; STONE, L. F. Rentabilidade das culturas de milho, soja e trigo em diferentes sistemas de preparo do solo. Pesquisa Agropecuária Brasileira, v. 32, n. 2, p. 75-79, 2002.

ZAGONEL, J. et al. Doses de nitrogênio e densidade de plantas com e sem regulador de crescimento afetando o trigo cultivarOR 1. Ciência Rural, v. 32, n. 1, p. 25-29, 2002. 